\title{
Inhibitory effects of methamphetamine on mast cell activation and cytokine/chemokine production stimulated by lipopolysaccharide in C57BL/6J mice
}

\author{
LI XUE ${ }^{1,2 *}, Y_{A N ~ G E N G}{ }^{2 *}$, MING LI $^{3}$, YAO-FENG JIN ${ }^{4}$, HUI-XUN REN ${ }^{1}$, XIA LI ${ }^{5}$, FENG WU $^{6}$, \\ BIAO WANG ${ }^{1}$, WEI-YING CHENG ${ }^{1}$, TENG $\mathrm{CHEN}^{7}$ and YAN-JIONG CHEN ${ }^{1}$ \\ ${ }^{1}$ Department of Immunology and Pathogenic Biology, Xi'an Jiaotong University School of \\ Basic Medical Sciences; ${ }^{2}$ Department of Laboratory, The Second Affiliated Hospital of Medical College of \\ Xi'an Jiaotong University; ${ }^{3}$ Department of Cardiovascular Surgery, The First Affiliated Hospital of \\ Medical College of Xi'an Jiaotong University, Xi'an, Shaanxi 710061; ${ }^{4}$ Department of Pathology, \\ The Second Affiliated Hospital Medical College of Xi'an Jiaotong University, Xi'an, Shaanxi 710004; \\ ${ }^{5}$ VIP Internal Medicine Department, Lanzhou University Second Hospital, Lanzhou, Gansu 730030; \\ ${ }^{6}$ Graduate Teaching and Experiment Centre, Xi'an Jiaotong University School of Basic Medical Sciences; \\ ${ }^{7}$ Forensic Medicine College of Xi'an Jiaotong University, Key Laboratory of The Health Ministry for \\ Forensic Medicine, Key Laboratory of The Ministry of Education for Environment and \\ Genes Related to Diseases, Xi'an, Shaanxi 710061, P.R. China
}

Received July 19, 2017; Accepted October 13, 2017

DOI: 10.3892/etm.2018.5837

\begin{abstract}
Previous studies have demonstrated that methamphetamine (MA) influences host immunity; however, the effect of MA on lipopolysaccharide (LPS)-induced immune responses remains unknown. Mast cells (MCs) are considered to serve an important role in the innate and acquired immune response, but it remains unknown whether MA modulates MC activation and LPS-stimulated cytokine production. The present study aimed to investigate the effect of MA on LPS-induced MC activation and the production of MC-derived cytokines in mice. Markers for MC activation, including cluster of differentiation 117 and the type I high affinity immunoglobulin E receptor, were assessed in mouse intestines. Levels of MC-derived cytokines in the lungs and
\end{abstract}

Correspondence to: Dr Yan-Jiong Chen, Department of Immunology and Pathogenic Biology, Xi'an Jiaotong University School of Basic Medical Sciences, 76 Yanta West Road, Xi'an, Shaanxi 710061, P.R. China

E-mail: chenyanjiong@126.com

"Contributed equally

Abbreviations: MA, methamphetamine; LPS, lipopolysaccharide; MCs, mast cells; NS, normal saline; BMMCs, bone marrow-derived mast cells; SCF, stem cell factor; TNF- $\alpha$, tumor necrosis factor- $\alpha$; IL, interleukin; CCL-5, chemokine ligand-5

Key words: methamphetamine, lipopolysaccharide, mast cell, cytokines, chemokines thymus were also examined. The results demonstrated that cytokines were produced in the bone marrow-derived mast cells (BMMCs) of mice. The present study demonstrated that MA suppressed the LPS-mediated MC activation in mouse intestines. MA also altered the release of MC cytokines in the lung and thymus following LPS stimulation. In addition, LPS-stimulated cytokines were decreased in the BMMCs of mice following treatment with MA. The present study demonstrated that MA may regulate LPS-stimulated MC activation and cytokine production.

\section{Introduction}

Methamphetamine hydrochloride (MA) is a widely abused psychostimulant with an estimated 35 million users worldwide; thus, it has become a public health problem (1). A number of animal and clinical studies have demonstrated that MA abuse induces immunosuppressive effects, thereby increasing susceptibility to infectious diseases (2). Lipopolysaccharide (LPS), an immunostimulant, may mediate the immune response associated with gram-negative bacterial infection. Although previous studies have demonstrated the detrimental effect of MA on host immunity $(3,4)$, the effect of MA following stimulation with LPS on the immune response has not yet been described.

It has been demonstrated that mast cells (MCs) serve an important role in innate and acquired immune responses $(5,6)$, such that certain diseases are associated with changes in the number of MCs at affected sites $(7,8)$. MCs are abundant at the borders of the external environment, including the intestinal mucosa where MCs function as sentinel cells during immune defense $(9,10)$. Cluster of differentiation 117 (CD117, also 
known as c-kit) is a primary receptor and MCs marker and it has been demonstrated that a loss-of-function mutation in c-kit causes MCs deficiency in mice (11). The type I high affinity immunoglobulin E receptor (FceRI) is an another receptor and marker of MCs that excites FceRI and activates MCs (12). It has been demonstrated that LPS induces rodent MCs to secrete a variety of cytokines, including tumor necrosis factor- $\alpha$ (TNF- $\alpha)$, interleukin (IL)-1 $\beta$, IL-4, IL-6, IL-10, IL-13 and chemokine ligand-5 (CCL-5) $(13,14)$. MC-mediated cytokine production is often greater than that from other immunocytes, including macrophages and T cells $(15,16)$. In addition, MCs serve an important role in the lung (17); indeed, thymic MCs have been implicated in infection-induced thymus involution (18). However, it is remains unknown whether MA modulates MCs activation and the subsequent production of cytokines stimulated by LPS.

The present study assessed the effect of MA on MC activation and release of cytokines stimulated by LPS in C57BL/6J mice. The expression of CD117 and FceRI was measured in mouse intestines and it was demonstrated that MCs released cytokines in the lung and thymus tissues following treatment with MA and LPS stimulation. To further verify the effect of MA on the response of MCs mediated by LPS, LPS-stimulated cytokine production following MA treatment in mouse bone marrow-derived mast cells (BMMCs) was examined. The results of the present study demonstrate that MA may regulate MC activation and LPS-stimulated cytokine production.

\section{Materials and methods}

Animals. A total of $48 \mathrm{C} 57 \mathrm{BL} / 6 \mathrm{~J}$ mice aged 6-week-old (weighing $20 \mathrm{~g} ; 24$ males: 24 females) were purchased from the Laboratory Animal Department of Xi'an Jiaotong University Medical School (Xi'an, China). C57BL/6J mice were housed in a specific pathogen-free facility (temperature, $22 \pm 3^{\circ} \mathrm{C}$; relative humidity, $60 \pm 5 \%$ ) maintained on a $12-\mathrm{h}$ light/dark cycle. All the mice had free access to food and water. Experiments were approved by the Animal Ethics Committee of Xi'an Jiaotong University and all treatment procedures were performed in accordance with the guidelines of the Institutional Animal Care and Use Committee of Xi'an Jiaotong University.

Reagents. MA was purchased from the National Institute for the Control of Pharmaceutical and Biological Products (Beijing, China). MA was dissolved in sterile 0.9\% physiological saline and injected intramuscularly (i.m.) at a dose of $5 \mathrm{mg}$ MA/kg. LPS (derived from Escherichia coli; serotype O55:B5; Sigma-Aldrich; Merck KGaA, Darmstadt, Germany) was dissolved in sterile saline and injected i.m. at a dose of $150 \mu \mathrm{g} / \mathrm{kg}$.

Animal treatments. The 6-week-old sex-matched C57BL/6J mice were randomly divided into 4 groups $(n=12)$, including a normal saline (NS) NS+NS group (control), a MA+NS group, an NS+LPS group and a MA+LPS group. Mice received four i.m. injections of either $5 \mathrm{mg} / \mathrm{kg}$ MA or NS at $2 \mathrm{~h}$ intervals. Mice then received one i.m. injection of either LPS $(150 \mu \mathrm{g} / \mathrm{kg})$ or NS $24 \mathrm{~h}$ following the first MA injection. The $5 \mathrm{mg} / \mathrm{kg}$ dose of MA was selected based on the results of a previous study (19) and a preliminary experiment in the present study indicated that $150 \mu \mathrm{g} / \mathrm{kg}$ LPS was the most appropriate dose. Mice were sacrificed by $\mathrm{CO}_{2}$ asphyxiation and tissues, including lung and thymus tissues, were obtained for histological analysis and cytokine measurement.

Immunohistochemistry. Intestine tissues were fixed in $10 \%$ formalin solution at room temperature for $24 \mathrm{~h}$, and then samples were embedded in paraffin and $5-\mu \mathrm{m}$ thick paraffin sections were prepared. The paraffin sections were deparaffinized and rehydrated in a descending alcohol series. Antigen retrieval was performed using a highly compressed heating method in a citrate buffer solution $\left(95^{\circ} \mathrm{C}, 5-10 \mathrm{~min}\right)$. Endogenous peroxidase activity was blocked using a solution of methanol- $0.3 \% \mathrm{H}_{2} \mathrm{O}_{2}$ incubated for $30 \mathrm{~min}$ at room temperature. Slides were incubated with the rabbit anti-mouse polyclonal antibodies for CD117 and FceRI (Beijing Bo Orson Biological Technology Co., Ltd., Beijing, China; dilutions, 1:100 and 1:200, respectively; cat. nos. bs-0672 and bs-13167R, respectively) overnight at $4^{\circ} \mathrm{C}$. Slides were then washed three times with PBS (pH 7.4) and incubated with a secondary antibody (anti-rabbit immunoglobulin G; dilution, 1:500; cat. no. bs-0295M; Beijing Bo Orson Biological Technology Co., Ltd.) for 2-3 h at room temperature. Finally, 3,3'-diaminobenzidine (Dr. Wuhan's Biological Engineering Co., Ltd., Wuhan, China) was used for coloration at room temperature for $5 \mathrm{~min}$. The chromogenic reaction was monitored every 3 min using an optical microscope. Following washing, sections were air-dried, dehydrated in ascending concentrations of ethanol, cleared with xylene and mounted under a cover slip with Permount. A total of 10 random fields per slide were examined and analyzed. The images were captured using a microscope (Leica microsystem GmbH, Wetzlar, Germany).

Reverse transcription-quantitative polymerase chain reaction (RT-qPCR). Total RNA was extracted from the lungs and thymus of mice and subsequently purified using a TRIzol kit (Invitrogen, Thermo Fisher Scientific Inc., Waltham, MA, USA). Nucleic acid concentration and purity (A260/A280) was measured using a microplate instrument. Residual genomic DNA was removed by incubation with RNase-free deoxyribonuclease (Takara Bio, Inc., Otsu, Japan). Reverse transcription was performed using a PrimeScript ${ }^{\mathrm{TM}}$ RT reagent kit (Takara Bio, Inc.) following the manufacturer's protocol. The resulting cDNA was subjected to qPCR using a Stratagene Mx 3005p real-time PCR Detection system (Agilent Technologies Inc., Santa Clara, CA, USA) using SYBR Green II (Takara Bio, Inc.) as a double-strand DNA-specific dye to quantify the expression of TNF- $\alpha$, IL-1 $\beta$, IL-6, IL-10, IL-4, IL-13 and CCL-5 in the lung and thymus of mice. The primer sequences were as follows: IL-1 $\beta$ forward, (F) 5'-GTCACAAGAAACCAT GGCACAT-3' and reverse, (R) 5'-GCCCATCAGAGGCAA GGA-3'; IL-4 F, 5'-ACGGAGATGGATGTGCCAAAC-3' and R, 5'-AGCACCTTGGAAGCCCTACAGA-3'; IL-6 F, 5'-CTG CAAGAGACTTCCATCCAGTT-3' and R, 5'-AGGGAAGGC CGTGGTTGT-3'; IL-10 F, 5'-GCCAGAGCCACATGCTCC TA-3' and R, 5'-GATAAGGCTTGGCAACCCAAGTAA-3'; IL-13 F, 5'-CGGCAGCATGGTATGGAGTG-3' and R, 5'-ATT GCAATTGGAGATGTTGGTCAG-3'; TNF- $\alpha$ F, 5'-GGCTGC CCCGACTACGT-3' and R, 5'-ACTTTCTCCTGGTATGAG 
ATAGCAAAT-3'; CCL-5 F, 5'-GGAGTATTTCTACACCAG CAGCAAG-3' and R, 5'-GGCTAGGACTAGAGCAAGCAA TGAC-3'; and glyceraldehyde 3-phosphate dehydrogenase (GAPDH) F, 5'-GCACCGTCAAGGCTGAGAAC-3' and R: 5'-TGGTGAAGACGCCAGTGGA-3'. All primers were synthesized by Bao Bioengineering Co., Ltd. (Dalian, China). The thermo cycling conditions of qPCR were as follows: Initial denaturation at $95^{\circ} \mathrm{C}$ for $30 \mathrm{sec}$; followed by 40 cycles at $95^{\circ} \mathrm{C}$ for $5 \mathrm{sec}$ and $60^{\circ} \mathrm{C}$ for $30 \mathrm{sec} ; 1$ cycle at $95^{\circ} \mathrm{C}$ for $60 \mathrm{sec}, 55^{\circ} \mathrm{C}$ for $30 \mathrm{sec}$, and $95^{\circ} \mathrm{C}$ for $30 \mathrm{sec}$. Following the completion of qPCR, specificity was assessed using a melting curve analysis. The results were quantified using the $2^{-\Delta \Delta C q}$ method (20). GAPDH was utilized as a reference gene.

Cytokine analysis of lung and thymus. The lungs and thymus of mice were homogenized at $4^{\circ} \mathrm{C}$ using tissue protein extraction reagent (Xi'an FengZu Biotechnology Co., Ltd., Xi'an, China) with a complete mini protease inhibitor cocktail and complete mini phosphatase inhibitor cocktail tablets (Roche Applied Science, Pleasanton, CA, USA), using 1 inhibitor tablet per $10 \mathrm{ml}$ tissue protein extraction reagent. Tissue homogenates were centrifuged at $12,000 \mathrm{xg}$ for $15 \mathrm{~min}$ at $4^{\circ} \mathrm{C}$. The total protein concentration in the supernatants of lung and thymus homogenates was determined using a BCA kit (Zhuhai Jian Kangyuan Biopharmaceutical Co., Jian Kangyuan Group Corporation, Guangdong, China). Supernatants were then diluted using a tissue protein extraction reagent to a final protein concentration of $500 \mu \mathrm{g} / \mathrm{ml}$ and stored at $80^{\circ} \mathrm{C}$ until further use. Cytokines TNF- $\alpha$, IL-1 $\beta$, IL-6, IL-10, IL-4, IL-13 and CCL-5 in the supernatants were measured using ELISA (eBioscience; Thermo Fisher Scientific Inc., Waltham, MA, USA; cat. nos. BMS607-3, BMS6002, BMS603-2, BMS614-2, BMS613, BMS6015 and BMS6009INST, respectively) following the manufacturer's protocol.

BMMC preparation and cytokine measurements. BMMCs were obtained from the femurs of 6-week-old C57BL/6J mice, following a previously described protocol (21). Cells were cultured at $37^{\circ} \mathrm{C}$ in RPMI 1640 medium (Gibco; Thermo Fisher Scientific) supplemented with $10 \%$ fetal bovine serum (FBS) (Gibco; Thermo Fisher Scientific, Inc.), $10 \mathrm{ng} / \mathrm{ml} \mathrm{IL-3,}$ $10 \mathrm{ng} / \mathrm{ml}$ stem cell factor (SCF), $2 \mathrm{mM} \mathrm{L}$-glutamine, $1 \mathrm{mM}$ sodium pyruvate, $1 \mathrm{mM}$ HEPES, $50 \mu \mathrm{M}$ 2-mercaptoethanol, $100 \mathrm{U} / \mathrm{ml}$ penicillin and $100 \mu \mathrm{g} / \mathrm{ml}$ streptomycin. IL-3 and SCF were purchased from PeproTech Inc. (Rocky Hill, NJ, USA). After 4 weeks, flow cytometry was used to identify whether BMMCs were composed of $>95 \%$ MCs. BMMCs were then incubated with fluorescence-labeled antibodies, including anti-CD117-flourescein isothocyanate (FITC; dilution, 1:100; cat. no. 553354; BD Biosciences Franklin Lakes, NJ, USA) and anti-FceR1-APC (dilution, 1:200, cat. no. 17-5898-82; eBioscience, Thermo Fisher Scientific Inc.) for $1 \mathrm{~h}$ at $4^{\circ} \mathrm{C}$.

BMMCs from C57BL/6J mice were treated with $100 \mu \mathrm{M} / 1$ MA and $1 \mu \mathrm{g} / \mathrm{ml}$ LPS for $24 \mathrm{~h}$ at $37^{\circ} \mathrm{C}$. The concentration of TNF- $\alpha$, IL-6, IL-4, IL-13 and CCL-5 cytokines present in the supernatants was then quantified using ELISA kits (eBioscience, Thermo Fisher Scientific Inc.; cat. nos. BMS607-3, BMS603-2, BMS613, BMS6015 and BMS6009INST) according to the manufacturer's protocol.
Statistical analysis. All the analysis was performed using SPSS software version 15.0 (SPSS, Inc., Chicago, IL, USA). One-way analysis of variance was used to determine the difference among groups. Comparisons of all pairs were completed using the Turkey-Kramer test. Data were expressed as the mean \pm standard error of the mean and $\mathrm{P}<0.05$ was considered to indicate a statistically significant difference.

\section{Results}

MA suppresses LPS-stimulated MC activation in the intestines of C57BL/6J mice. C57BL/6J mice received four i.m. injections of MA $(5 \mathrm{mg} / \mathrm{kg})$ or saline and were then injected with LPS or saline $24 \mathrm{~h}$ following the first MA injection. Fig. 1 presents the results of immunohistochemical staining for $\mathrm{CD}_{117^{+}}$and FceRI ${ }^{+}$in C57BL/6J mice. NS+LPS mice exhibited a significant increase in intestinal $\mathrm{CD} 117^{+}$and FceRI ${ }^{+}$compared with the NS+NS group $(\mathrm{P}<0.05$; Fig. 1B and D). No effect on $\mathrm{CD}_{117^{+}}$or FceRI ${ }^{+}$cells was identified in MA+NS treated mice. However, it was demonstrated that significantly fewer intestinal $\mathrm{CD} 117^{+}$and $\mathrm{Fc}_{\mathrm{CRI}}{ }^{+}$cells were present in MA+LPS treated mice, compared with mice that received NS+LPS $(\mathrm{P}<0.05$; Fig. 1B and D).

MA suppresses LPS-stimulated production of inflammatory cytokines in the lungs of C57BL/6J mice. Mice treated with NS+LPS exhibited a significant increase in the mRNA and protein levels of the pro-inflammatory cytokines TNF- $\alpha$, IL- $1 \beta$ and IL- 6 in the lungs, compared with NS+NS mice $(\mathrm{P}<0.05$; Fig. 2). MA+NS treatment had no effect on cytokine production. However, the mRNA and protein levels of all the pro-inflammatory cytokines were significantly decreased in the MA+LPS group, compared with mice in treated with NS+LPS $(\mathrm{P}<0.05$; Fig. 2). NS+LPS treatment induced a significant increase in IL-10 mRNA and protein expression $(\mathrm{P}<0.05$; Fig. 2). No significant difference in IL-10 production was identified between the MA+NS and the NS+NS groups; however, MA treatment significantly suppressed the LPS-mediated increase in IL-10 mRNA and protein expression $(\mathrm{P}<0.05$; Fig. 2).

MCs increase in number following the T helper 2 (Th2) response. Therefore, the effect of MA on LPS-stimulated Th2 cytokine/chemokine production in the lung was assessed. NS+LPS treatment significantly increased the mRNA and protein expression of the Th2 cytokines/chemokines IL-4, IL-13 and chemokine ligand-5 (CCL-5) in the lungs of mice $(\mathrm{P}<0.05$; Fig. 2). MA+NS treatment had no significant effect on the production of Th2 cytokines/chemokines at either level in the lungs of mice. However, the mRNA and protein levels of Th2 cytokines/chemokines were significantly decreased in MA+LPS mice, compared with mice that received NS+LPS (P<0.05; Fig. 2).

MA suppresses the LPS-stimulated production of inflammatory cytokines in the thymus of C57BL/6J mice. NS+LPS treatment significantly increased the production of the pro-inflammatory cytokines TNF- $\alpha$, IL-1 $\beta$ and IL- 6 at the mRNA and protein level in the thymus of mice compared with the NS+NS group $(\mathrm{P}<0.05$; Fig. 3A and B). No significant differences were identified in the mRNA or protein expression of thymic pro-inflammatory 
A

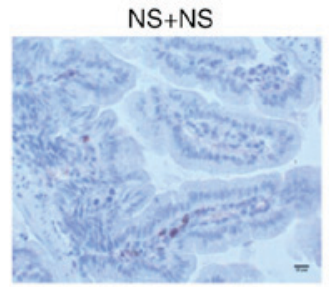

NS+LPS

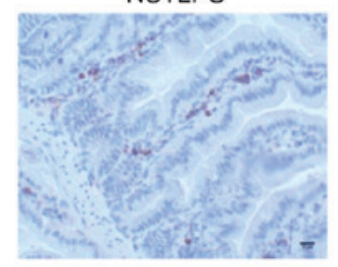

C

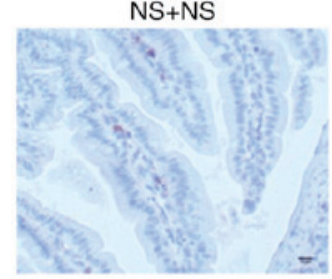

NS+LPS

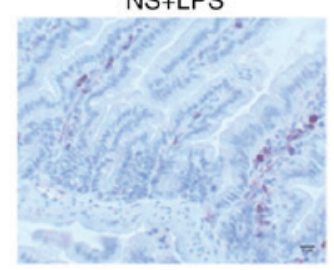

$\mathrm{MA}+\mathrm{NS}$

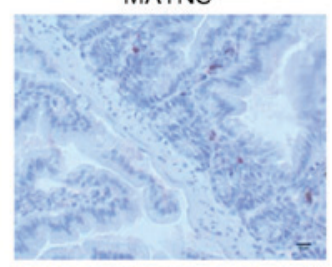

MA+LPS

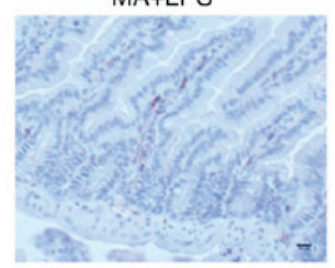

$\mathrm{MA}+\mathrm{NS}$

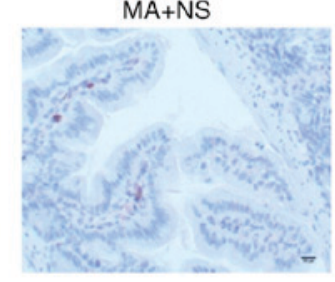

MA+LPS

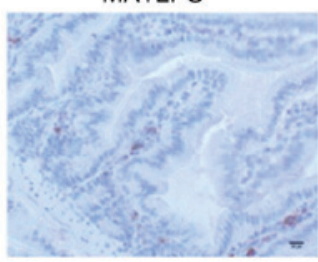

B
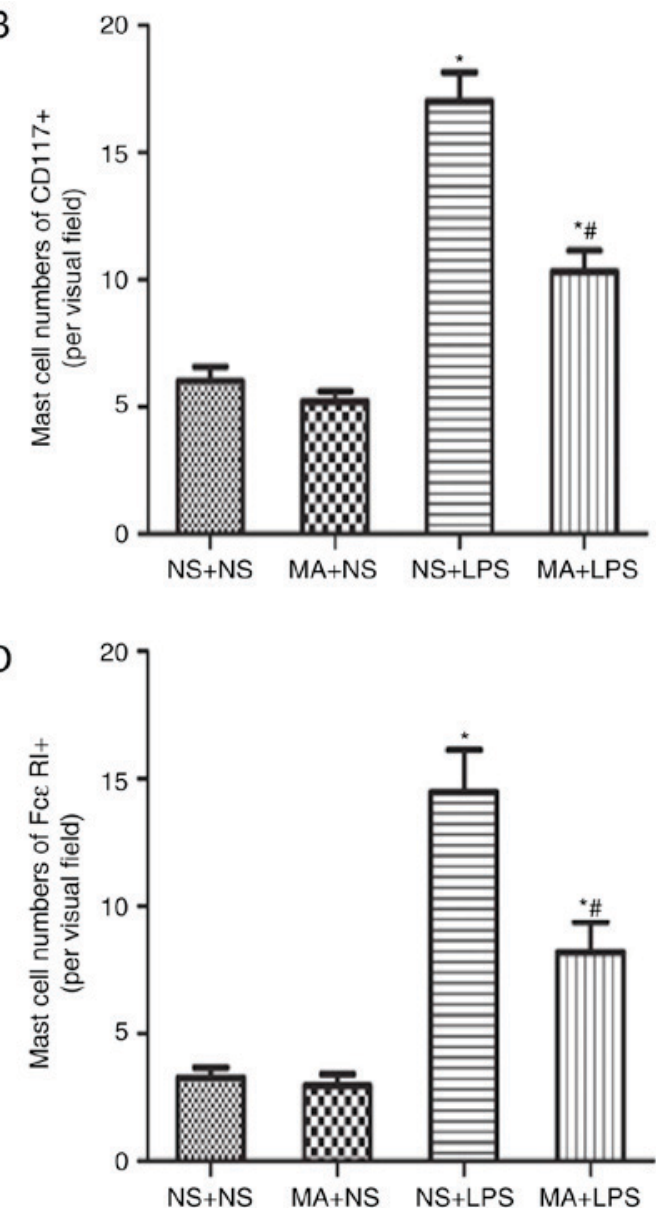

Figure 1. Effect of MA on LPS-stimulated MC activation in the intestines of C57BL/6J mice. (A) Anti-CD117 and (C) FceRI immunoreactivity of intestines from C57BL/6J mice. Brown stained cells were defined as CD117 or FceRI-positive cells. Stained sections were examined under a light microscope (magnification, $\mathrm{x} 400$ ). Scale bar $=50 \mu \mathrm{m}$. Quantification of immunohistochemical staining for (B) anti-CD117 (D) FceRI. Data are expressed as the mean \pm standard error of the mean $(\mathrm{n}=12) .{ }^{*} \mathrm{P}<0.05$ vs. NS+NS group; ${ }^{\prime} \mathrm{P}<0.05$ vs. NS+LPS group. MA, methamphetamine; LPS, lipopolysaccharide; CD117, cluster of differentiation 117; FceRI, type I high affinity immunoglobulin E receptor; NS, normal saline.

cytokines between mice treated with MA+NS and those treated with NS+NS. However, the mRNA and protein levels of the pro-inflammatory cytokines were significantly reduced in the thymus of the mice treated with MA+LPS compared with the NS+LPS group ( $\mathrm{P}<0.05$; Fig. 3$)$.

NS+LPS treatment significantly increased the mRNA and protein levels of the anti-inflammatory cytokine IL-10 in the thymus of mice ( $\mathrm{P}<0.05$; Fig. 3). MA+NS treatment alone had no effect on thymic IL-10 mRNA or protein expression. However, MA treatment significantly suppressed the LPS-stimulated increase in IL-10 mRNA and protein expression in the thymus of mice compared with the NS+NS group ( $\mathrm{P}<0.05$; Fig. 3 ).

NS+LPS treated mice exhibited a significant increase in the production of the Th2 cytokine/chemokines IL-4, IL-13 and CCL-5 at the mRNA and protein levels in the thymus of mice $(\mathrm{P}<0.05$; Fig. 3). No difference in the expression of Th2 cytokines/chemokine was observed between MA+NS treated mice and the NS+NS group. However, the expression of Th2 cytokine/chemokine mRNA and protein was significantly reduced in the group treated with MA+LPS, compared with mice that received NS+LPS treatment $(\mathrm{P}<0.05$; Fig. 3$)$.

MA suppresses the LPS-stimulated inflammatory cytokine production in the BMMCs of C57BL/6J mice. To verify the suppressive effects of MA on LPS-stimulated cytokine production, BMMCs were cultured and supernatant cytokine levels were measured using ELISA. BMMCs produced significantly higher levels of TNF- $\alpha$, IL-6, IL-4, IL-13 and CCL-5 in LPS-treated mice compared with NS+NS mice $(\mathrm{P}<0.05$; Fig. 4). However, a significant decrease in cytokine/chemokine production was identified in the BMMCs of mice in the MA+LPS group compared with the LPS group $(\mathrm{P}<0.05$; Fig. 4). IL-1 $\beta$ and IL-10 were not measured in BMMCs, as the concentrations were too low.

\section{Discussion}

MA is a potent stimulant of the central nervous system and its abuse causes severe psychological and physical effects. Previous studies have revealed that MA negatively impacts immune responses, which may contribute to the higher rate and rapid progression of certain infections found in drug abusers $(22,23)$. The present study therefore assessed the effects of MA on MC activation and cytokine/chemokine production in $\mathrm{C} 57 \mathrm{BL} / 6 \mathrm{~J}$ mice that received LPS stimulation.

The results demonstrated that MA treatment suppressed LPS-mediated MC activation in the intestines of C57BL/6J mice. MCs are concentrated at interfaces between the host and 

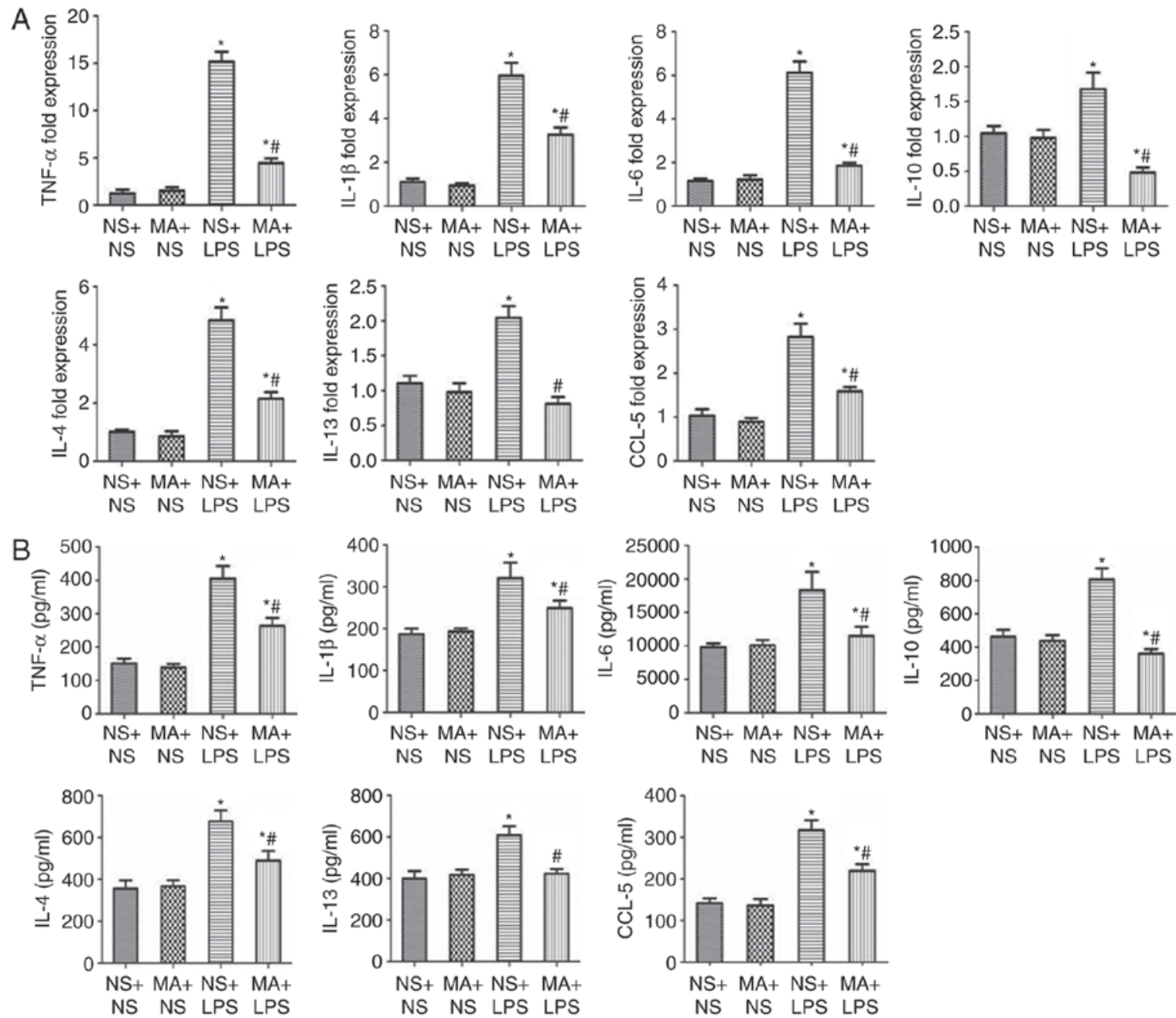

Figure 2. Effect of MA on LPS-stimulated cytokine expression in the lungs of C57BL/6J mice. C57BL/6J mice were treated with four doses of NS or $5 \mathrm{mg} / \mathrm{kg}$ MA at $2 \mathrm{~h}$ intervals, followed by $150 \mu \mathrm{g} / \mathrm{kg}$ saline or LPS for $24 \mathrm{~h}$. Lungs were then harvested and analyzed for cytokine (A) protein expression using ELISA or (B) mRNA expression using reverse transcription quantitative polymerase chain reaction. Data are expressed as the mean \pm standard error of the mean $(\mathrm{n}=12) .{ }^{*} \mathrm{P}<0.05$ vs. NS+NS group; ${ }^{*} \mathrm{P}<0.05$ vs. NS+LPS group. MA, methamphetamine; LPS, Lipopolysaccharide; NS, normal saline; TNF- $\alpha$, tumor necrosis factor- $\alpha$; IL, interleukin; CCL-5, chemokine ligand-5.

environment, including the intestinal tract, where they limit the spread of invading pathogens (24). MCs are considered to function as effecter cells during the innate and adaptive immune responses (25-27). CD117 and FceRI are primary MC surface receptors associated with MC activation (7,12,28-30). The present study demonstrated that MA+LPS treatment significantly decreased the expression of intestinal CD117 and FceRI. However, the effect of MA and LPS on MCs themselves was not assessed in the present study. Therefore, further experiments should be conducted to investigate the expression profiles of MC cytokines stimulated with varying doses of LPS and MA.

Previous studies have demonstrated that LPS induces MCs to secrete cytokines, thus promoting the innate and adaptive immune responses $(31,32)$. The most studied MC derived cytokine in the innate immune response is TNF- $\alpha$, which induces the early influx of neutrophils and clearance of pathogens (33-35). It has been demonstrated that IL-6 produced by MCs increases the survival rates of patients with Klebsiella pneumoniae and sepsis by stimulating neutrophil activity (36). IL-10 is an anti-inflammatory cytokine which suppresses the synthesis of inflammatory cytokines, including TNF- $\alpha$ and IL-6 (37). It has been demonstrated that MCs can mediate negative immunomodulatory functions by producing IL-10 in response to chronic irradiation with UVB light (38). In addition, certain MC derived Th2-type cytokines, including IL-4 and IL-13, influence B-cell development and function (11). MCs are also an important source of chemokines, including CCL5, which is involved in Th2-type responses (10). The results of the present study demonstrate that MA treatment suppresses MC derived, LPS-stimulated, inflammatory cytokine production in the lungs and thymus of $\mathrm{C} 57 \mathrm{BL} / 6 \mathrm{~J}$ mice. It was also revealed that MA has a suppressive effect on the production of LPS-stimulated inflammatory cytokines in the BMMCs of mice. The results indicated that MA abuse leads to immunosuppressive effects, which may increase the risk of infection. However, the present study did not assess the effect of MA on other immune cells. Further studies are required to improve understanding regarding the effects of MA on immune function.

In conclusion, the present study demonstrated that MA may be involved in the regulation of LPS-stimulated MCs activation and cytokine production. This may be responsible 

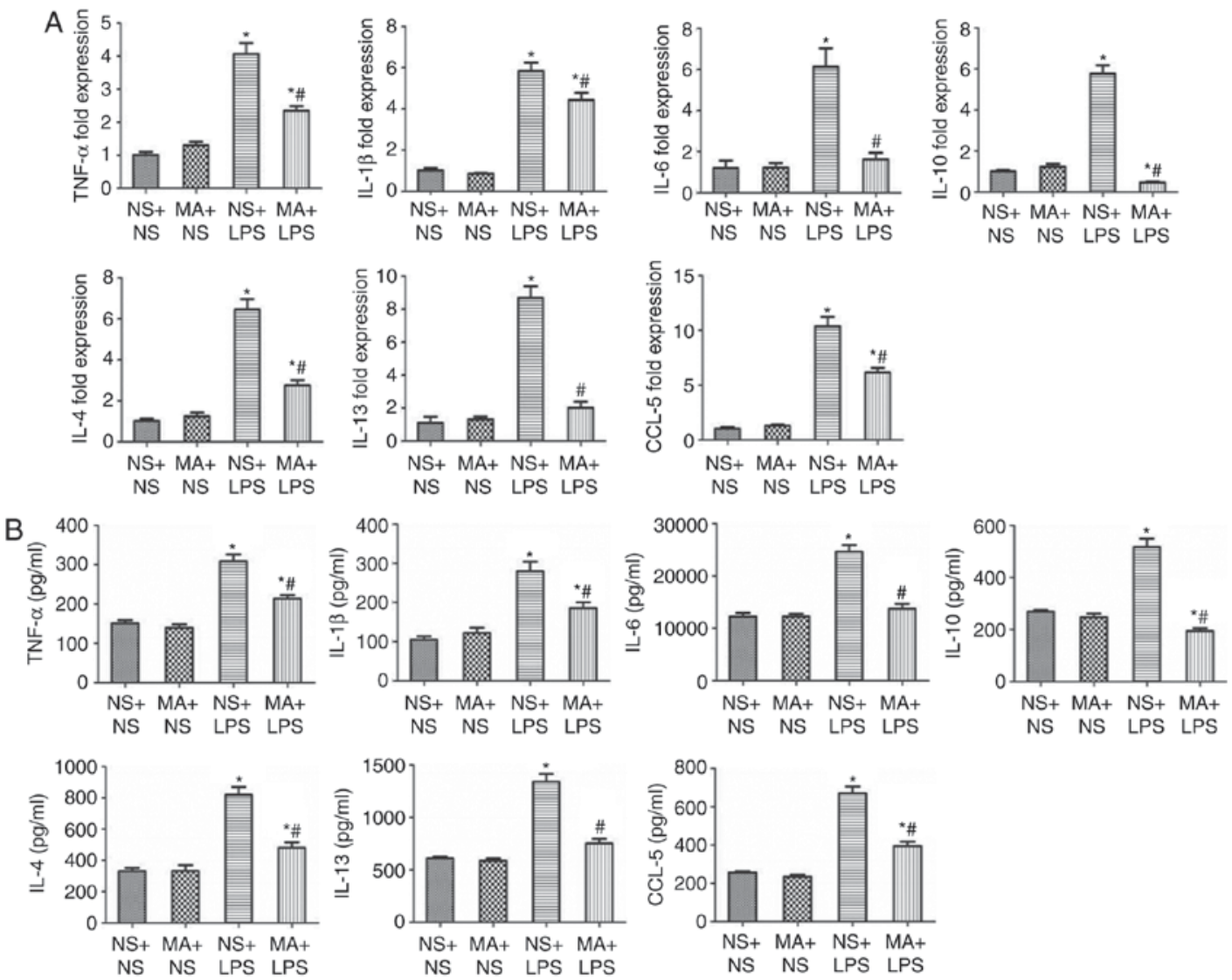

Figure 3. Effect of MA on LPS-stimulated cytokine expression in the thymus of C57BL/6J mice. C57BL/6J mice were treated with four doses of NS or $5 \mathrm{mg} / \mathrm{kg}$ MA at $2 \mathrm{~h}$ intervals, followed by $150 \mu \mathrm{g} / \mathrm{kg}$ saline or LPS for $24 \mathrm{~h}$. The Thymus was harvested and analyzed for cytokine (A) protein expression using ELISA or (B) mRNA expression by reverse transcription quantitative polymerase chain reaction. Data are expressed as the mean \pm standard error of the mean ( $\mathrm{n}=12$ ). ${ }^{*} \mathrm{P}<0.05$ vs. NS+NS group; ${ }^{\mathrm{P}}<0.05$ vs. NS+LPS group. MA, methamphetamine; LPS, lipopolysaccharide; NS, normal saline; TNF- $\alpha$, tumor necrosis factor $\alpha$; IL, interleukin; CCL-5, chemokine ligand-5.
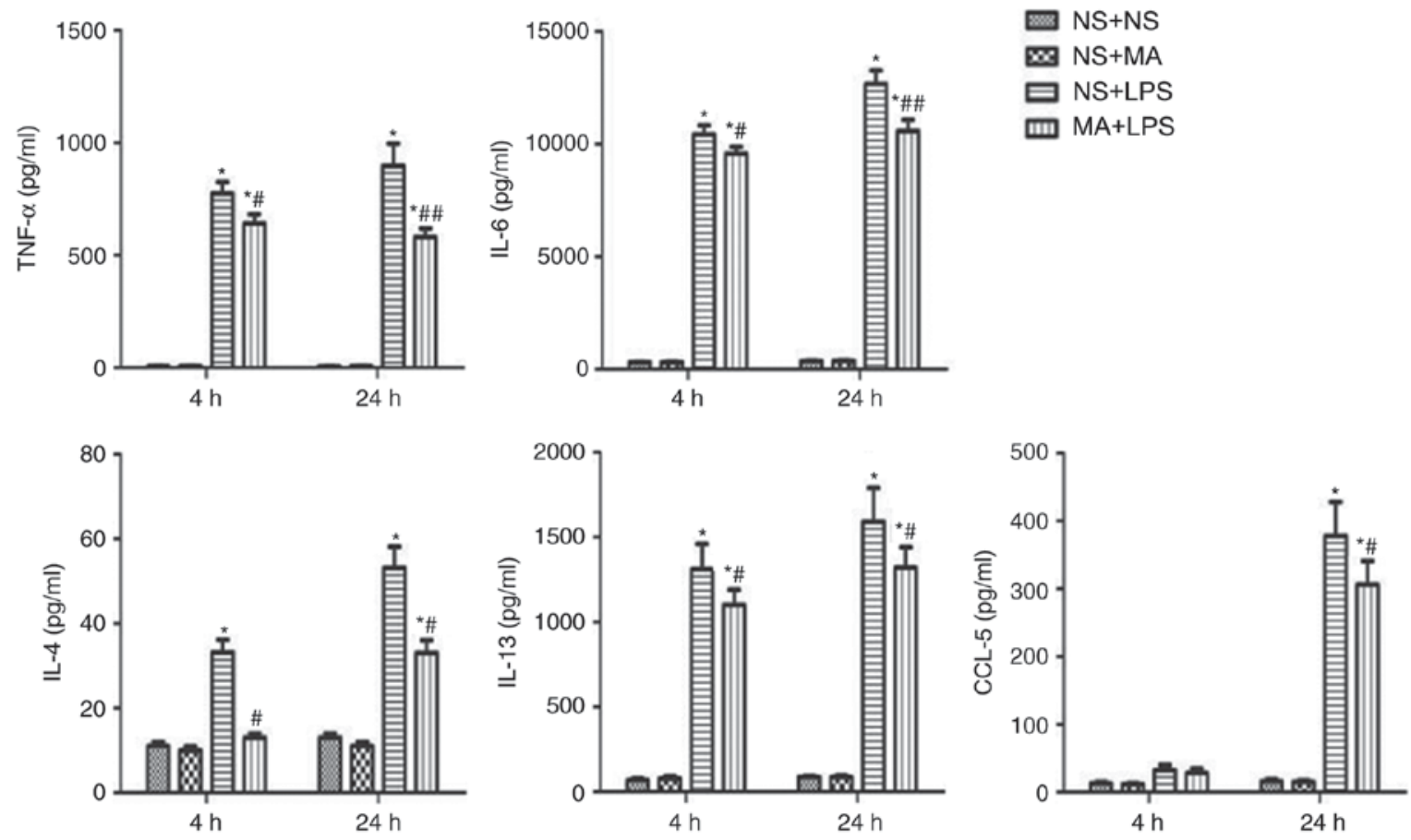

Figure 4. Effect of MA on LPS-stimulated cytokine production in the BMMCs of C57BL/6J mice. BMMCs were treated with NP, MA and/or LPS at the indicated concentrations (MA, $100 \mu \mathrm{M} ; \mathrm{LPS}, 1 \mu \mathrm{g} / \mathrm{ml}$; MA+LPS, $100 \mu \mathrm{M} \mathrm{MA}+1 \mu \mathrm{g} / \mathrm{ml} \mathrm{LPS}$ ) for $4 \mathrm{~h}$ or $24 \mathrm{~h}$ at $37^{\circ} \mathrm{C}$. Following treatment, cytokine concentrations in cell supernatants were evaluated using ELISA. Data are expressed as the mean \pm standard error of the mean of four samples. ${ }^{*}<0.05$ vs. NS+NS group at the same time-point; ${ }^{*} \mathrm{P}<0.05$ vs. LPS group at the same time-point; ${ }^{\# \#} \mathrm{P}<0.01 \mathrm{vs}$. NS+LPS group at the same time-point. MA, methamphetamine; LPS, Lipopolysaccharide; BMMCs, bone marrow-derived mast cells; TNF- $\alpha$, tumor necrosis factor $\alpha$; IL, interleukin; CCL-5, chemokine ligand-5. 
for the immune dysfunction and increased susceptibility to infectious diseases associated with MA abuse. Further studies are required to explore the mechanism underlying the immunomodulatory effects of MA.

\section{Acknowledgements}

The present study was supported by the National Natural Science Foundation of China (grant nos. 81273196 and 81430048) and the Fundamental Research Funds for the Central Universities of China (grant no. xjj2016109).

\section{References}

1. Chomchai $\mathrm{C}$ and Chomchai S: Global patterns of methamphetamine use. Curr Opin Psychiatr 28: 269-274, 2015

2. Mravčík V, Florián Z, Nečas V and Stolfa J: Infectious and other somatic comorbidity in problem drug users-results of a cross-sectional study with medical examination. Epidemiol Mikrobiol Imunol 65: 56-62, 2016 (In Czech).

3. Patel D, Desai GM, Frases S, Cordero RJ, DeLeon-Rodriguez CM, Eugenin EA, Nosanchuk JD and Martinez LR: Methamphetamine enhances Cryptococcus neoformans pulmonary infection and dissemination to the brain. MBio 4: pii: e00400-13, 2013.

4. Peerzada H, Gandhi JA, Guimaraes AJ, Nosanchuk JD and Martinez LR: Methamphetamine administration modifies leukocyte proliferation and cytokine production in murine tissues Immunobiology 218: 1063-1068, 2013.

5. Arthur G and Bradding P: New developments in mast cell biology: Clinical implications. Chest 150: 680-693, 2016.

6. Yamanishi Y and Karasuyama H: Basophils and mast cells in immunity and inflammation. Semin Immunopathol 38: 535-537, 2016.

7. Galli SJ, Kalesnikoff J, Grimbaldeston MA, Piliponsky AM, Williams CM and Tsai M: Mast cells as 'tunable' effecto and immunoregulatory cells: Recent advances. Annu Rev Immunol 23: 749-786, 2005.

8. Ryan JJ, Kashyap M, Bailey D, Kennedy S, Speiran K, Brenzovich J, Barnstein B, Oskeritzian C and Gomez G: Mast cell homeostasis: A fundamental aspect of allergic disease. Crit Rev Immunol 27: 15-32, 2007

9. Galli SJ, Maurer M and Lantz CS: Mast cells as sentinels of innate immunity. Curr Opin Immunol 11: 53-59, 1999.

10. Marshall JS: Mast-cell responses to pathogens. Nat Rev Immunol 4: 787-799, 2004

11. Galli SJ, Nakae S and Tsai M: Mast cells in the development of adaptive immune responses. Nat Immunol 6: 135-142, 2005.

12. Abramson $\mathrm{J}$ and Pecht I: Regulation of the mast cell response to the type $1 \mathrm{Fc}$ epsilon receptor. Immunol Rev 217: 231-254, 2007.

13. Supajatura V, Ushio H, Nakao A, Akira S, Okumura K, Ra C and Ogawa H: Differential responses of mast cell Toll-like receptors 2 and 4 in allergy and innate immunity. J Clin Invest 109 : 1351-1359, 2002.

14. Sandig H and Bulfone-Paus S: TLR signaling in mast cells: Common and unique features. Front Immunol 3: 185, 2012.

15. Leal-Berumen I, Conlon P and Marshall JS: IL-6 production by rat peritoneal mast cells is not necessarily preceded by histamine release and can be induced by bacterial lipopolysaccharide. J Immunol 152: 5468-5476, 1994.

16. Gupta AA, Leal-Berumen I, Croitoru K and Marshall JS: Rat peritoneal mast cells produce IFN-gamma following IL-12 treatment but not in response to IgE-mediated activation. J Immunol 157: 2123-2128, 1996.

17. Moiseeva EP and Bradding P: Mast cells in lung inflammation. Adv Exp Med Biol 716: 235-269, 2011.
18. Marinova T, Philipov S and Aloe L: Nerve growth factor immunoreactivity of mast cells in acute involuted human thymus. Inflammation 30: 38-43, 2007.

19. Buchanan JB, Sparkman NL and Johnson RW: A neurotoxic regimen of methamphetamine exacerbates the febrile and neuroinflammatory response to a subsequent peripheral immune stimulus. J Neuroinflammation 7: 82, 2010.

20. Livak KJ and Schmittgen TD: Analysis of relative gene expression data using real-time quantitative PCR and the 2(-Delta Delta C(T)) method. Methods 25: 402-408, 2001.

21. Xue L, Li X, Ren HX, Wu F, Li M, Wang B, Chen FY, Cheng WY, Li JP, Chen YJ and Chen T: The dopamine D3 receptor regulates the effects of methamphetamine on LPS-induced cytokine production in murine mast cells. Immunobiology 220: 744-752, 2015.

22. Najera JA, Bustamante EA, Bortell N, Morsey B, Fox HS, Ravasi T and Marcondes MC: Methamphetamine abuse affects gene expression in brain-derived microglia of SIV-infected macaques to enhance inflammation and promote virus targets. BMC Immunol 17: 7, 2016.

23. Loftis JM: Commentary: Methamphetamine mediates immune dysregulation in a murine model of chronic viral infection. Front Microbiol 6: 1473, 2015

24. Abraham SN and St John AL: Mast cell-orchestrated immunity to pathogens. Nat Rev Immunol 10: 440-452, 2010.

25. Galli SJ, Grimbaldeston M and Tsai M: Immunomodulatory mast cells: Negative, as well as positive, regulators of immunity. Nat Rev Immunol 8: 478-486, 2008.

26. Stelekati E, Orinska Z and Bulfone-Paus S: Mast cells in allergy: Innate instructors of adaptive responses. Immunobiology 212 : 505-519, 2007.

27. Rao KN and Brown MA: Mast cells: Multifaceted immune cells with diverse roles in health and disease. Ann N Y Acad Sci 1143: 83-104, 2008

28. Gilfillan AM and Tkaczyk C: Integrated signalling pathways for mast-cell activation. Nat Rev Immunol 6: 218-230, 2006.

29. Kinet JP: The high-affinity IgE receptor (Fc epsilon RI): From physiology to pathology. Annu Rev Immunol 17: 931-972, 1999.

30. Rivera J and Gilfillan AM: Molecular regulation of mast cell activation. J Allergy Clin Immunol 117: 1214-1226, 2006.

31. Dietrich N, Rohde M, Geffers R, Kröger A, Hauser H, Weiss S and Gekara NO: Mast cells elicit proinflammatory but not type I interferon responses upon activation of TLRs by bacteria. Proc Natl Acad Sci USA 107: 8748-8753, 2010.

32. Takenaka H, Ushio H, Niyonsaba F, Jayawardana ST, Hajime S, Ikeda S, Ogawa H and Okumura K: Synergistic augmentation of inflammatory cytokine productions from murine mast cells by monomeric IgE and toll-like receptor ligands. Biochem Biophys Res Commun 391: 471-476, 2010.

33. Henz BM, Maurer M, Lippert U, Worm M and Babina M: Mast cells as initiators of immunity and host defense. Exp Dermatol 10: $1-10,2001$.

34. Maurer M, Theoharides T, Granstein RD, Bischoff SC, Bienenstock J, Henz B, Kovanen P, Piliponsky AM, Kambe N, Vliagoftis $\mathrm{H}$, et al: What is the physiological function of mast cells? Exp Dermatol 12: 886-910,2003.

35. Maurer M and Metz M: The status quo and quo vadis of mast cells. Exp Dermatol 14: 923-929, 2005.

36. Sutherland RE, Olsen JS, McKinstry A, Villalta SA and Wolters PJ: Mast cell IL-6 improves survival from Klebsiella pneumonia and sepsis by enhancing neutrophil killing. J Immunol 181: 5598-5605, 2008.

37. Glocker EO, Kotlarz D, Klein C, Shah N and Grimbacher B: IL-10 and IL-10 receptor defects in humans. Ann N Y Acad Sci 1246: 102-107, 2011.

38. Grimbaldeston MA, Nakae S, Kalesnikoff J, Tsai M and Galli SJ: Mast cell-derived interleukin 10 limits skin pathology in contact dermatitis and chronic irradiation with ultraviolet B. Nat Immunol 8: 1095-1104, 2007. 